\title{
Evaluation of the environmental parameters controlling the vulnerability of the coastal marine regions
}

\author{
M. Iosjpe \\ Norwegian Radiation Protection Authority, Grini næringspark 13, 1332 Østerås, Norway
}

\begin{abstract}
The evaluation of environmental vulnerability is one of the key factors in need of consideration during the improvement of decision-making systems and the development of response strategies to radionuclide release into marine regions. Environmental marine modelling has to simultaneously describe the dispersion of radionuclides in water and sediment phases; bioaccumulation of radionuclides in biota and finally, dose assessments. It is obvious that such an approach comes up against the problem of complexity and the need for a large set of parameters. The sensitivity analysis of the model parameters can contribute to a better understanding of experimental data as well as define parameters which can play a key role in the evaluation of environmental vulnerability. In the present paper sensitivity analysis has been carried out using the compartment modelling approach for assessment of the environmental vulnerability as dose to man. The sensitivity analysis shows that the influence of model parameters can vary greatly depending on the concrete radionuclude and on the marine region. It is also shown that the results of the sensitivity parameter analysis can contribute to the process of defining which parameters can play an important role in the dose assessment and the evaluation of environmental vulnerability.
\end{abstract}

\section{INTRODUCTION}

The evaluation of the environmental sensitivity is one of the key factors in need of consideration in the improvement of decision-making systems and the development of response strategies to radionuclide release into marine regions.

Environmental marine modelling has to simultaneously describe the dispersion of radionuclides in water and sediment phases; bioaccumulation of radionuclides in biota and finally, dose assessments. It is obvious that such an approach comes up against the problem of complexity and the need for a large set of parameters. The sensitivity analysis of the model parameters can contribute to the process of defining which parameters can play a key role in the evaluation of environmental vulnerability.

In the present paper the environmental sensitivity has been considered as a dose to man according to the scenario developed under the EMRAS II program [1]: a release scenario where a single deposition of $1000 \mathrm{~Bq} / \mathrm{m}^{2}$ of radionuclides ${ }^{137} \mathrm{Cs},{ }^{90} \mathrm{Sr},{ }^{131} \mathrm{I}$ and ${ }^{239} \mathrm{Pu}$ is released into all marine regions (all surface model compartments, which are shown in Figure 1).

\section{METHODOLOGY}

Evaluation of the environmental sensitivity for different marine coastal areas shows that the radiation doses for adults are significantly higher than the doses calculated to children. Further, the doses calculated for the first year dominate the doses during the second and tenth year after releases of radionuclides [2]. Therefore, the doses to adults for the first year after radionuclide deposition have been used for the sensitivity analysis of the model parameters.

In the present paper every simulation has been carried out using the NRPA compartment model for dose assessment to man and biota, which includes the processes of advection of radioactivity between water compartments, sedimentation, diffusion of radioactivity through pore water in sediments, particle mixing, pore water mixing and a burial process of radioactivity in deep sediment layers $[3,4]$. The model 


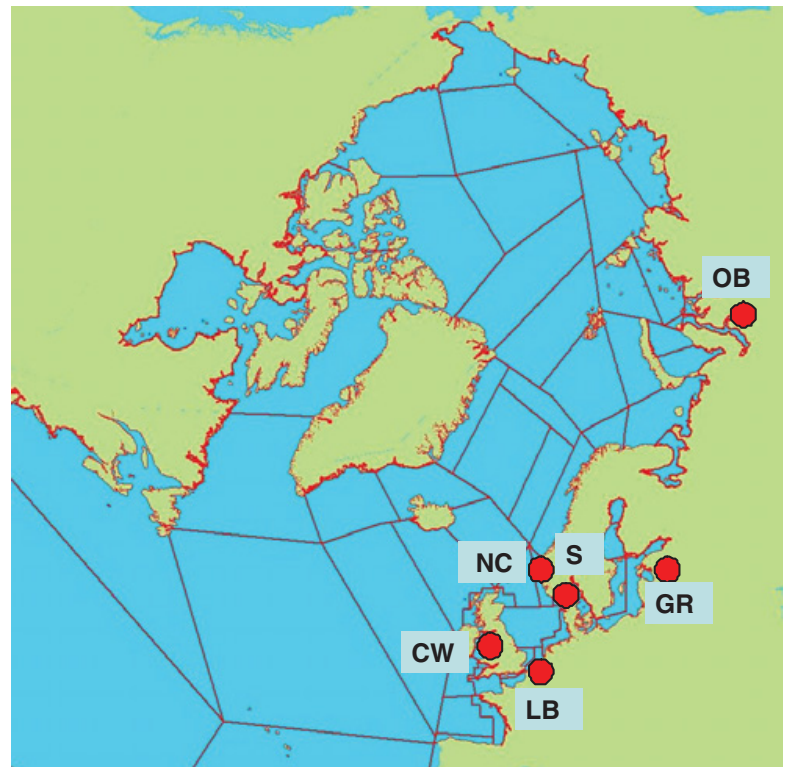

Figure 1. The surface structure of the NRPA box model and location of the selected marine regions.

takes into account the fact that contaminants are partitioned between the water phase and suspended sediment material in the coastal environment. The contamination of biota is further calculated from the radionuclide concentrations in filtered seawater. Doses to man are calculated on the basis of seafood consumption provided by [5] for the population of the coastal regions with the same consumption for all evaluated shallow environments.

The sensitivity parameter analysis has been provided on the basis of the local sensitivity index $\left(\mathrm{S}^{(\mathrm{L})}\right)[7]$ :

$$
\mathrm{S}^{(\mathrm{L})}(\mathrm{P})=\left(\frac{\mathrm{dV}^{(\mathrm{S})}}{\mathrm{dP}}\right)_{\mathrm{P}_{0}} \frac{\mathrm{P}_{0}}{\mathrm{~V}_{0}^{(\mathrm{S})}},
$$

where $\mathrm{V}^{(\mathrm{S})}$ and $\mathrm{P}$ correspond to state variables (for example, doses to man) and parameters which are under evaluation; $\mathrm{P}_{0}$ and $\mathrm{V}_{0}^{(\mathrm{S})}$ correspond to the basic values of the parameter $\mathrm{P}$ and the state variable $\mathrm{V}^{(\mathrm{S})}$. In the present paper the values for $\mathrm{P}_{0}$ and $\mathrm{V}_{0}^{(\mathrm{S})}$ correspond to results provided by [2].

\section{RESULTS AND DISCUSSION}

In accordance to [2], the calculations were carried out for six shallow marine coastal environments: Cumbrian waters of the Irish Sea (CW), Lyme Bay on the English Channel (LB), North Sea off the Norwegian coasts (NC), Skagerrak (S), the Gulf of Riga on the Baltic Sea (GR), and Ob Bay on the Kara Sea $(\mathrm{OB})$. The selected marine regions are shown in Figure 1.

Before proceeding to the evaluation of the environmental parameters, it is necessary to note that the assumptions about seafood consumption and the release scenario of radionuclides have a great impact on dose assessment. For example, the pale color in Figure 2a corresponds to the results of dose calculations from ${ }^{137} \mathrm{Cs}$ release, where the same assumptions about the levels of seafood consumption for the population of the coastal regions, provided by [5] have been used in all marine locations [2], while the dark color corresponds to calculations where site specific information about average seafood consumption, provided by [5] and [6] have been used for the Cumbrian waters (CW) and for the 


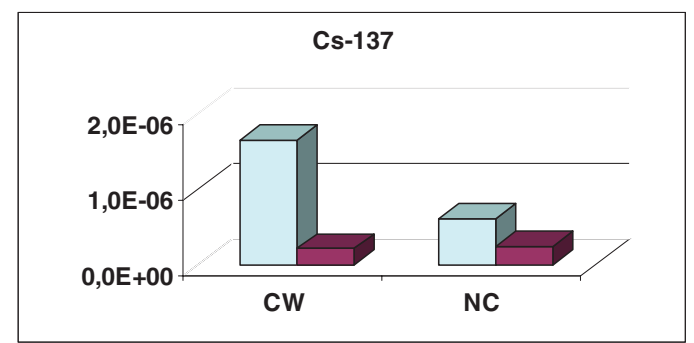

a)

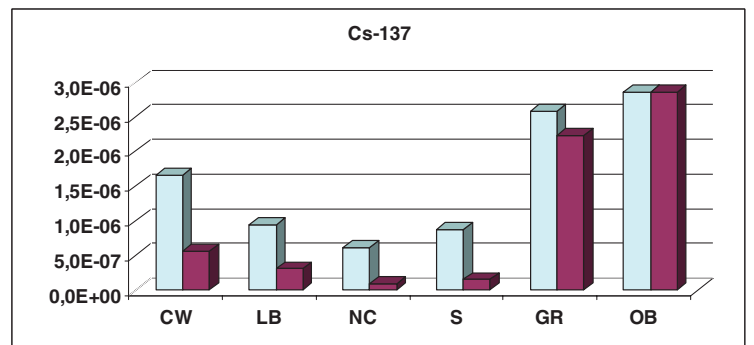

b)

Figure 2. Doses (Sv) for different assumption about levels of seafood consumption (a) and for different release scenarios (b).

Norwegian coastal waters (NC), respectively. Results of calculations show a significant decrease in the doses for the both regions because the average seafood consumption according to [5,6] is lower than consumption evaluated by [5] for the population of the coastal regions. In addition, dose calculations according to [2] indicate a significant difference between marine locations while calculations, based on average seafood consumption indicate the same sensitivity of the $\mathrm{CW}$ and NC regions, approximately. Further, Figure $2 \mathrm{~b}$ shows the differences between the two different release scenarios for ${ }^{137} \mathrm{Cs}$. Both scenarios involve a single deposition of $1000 \mathrm{~Bq} / \mathrm{m}^{2}$, but the pale color corresponds to the deposition to all surface marine compartments $[1,2]$, while the dark color corresponds to calculations where only a single selected region was contaminated. Results in figure $2 b$ indicate that for some regions $(\mathrm{Ob}$ Bay and Gulf of Riga) the differences are not very big while for other marine locations results varies greatly. Thus, different approaches concerning these main initial conditions for the evaluation of the environmental sensitivity can lead to significant differences in final results of analysis.

\subsection{Sensitivity analysis of the model parameters}

In the present study the following parameters have been considered: parameters describing the dispersion of radionuclides between water compartment as advection rates (fl), where parameter " $\mathrm{fl}$ " corresponds to maximum water exchange for the evaluated compartment and adjacent compartments; parameters describing water-sediment interactions as sediment reworking rate $\left(\mathrm{R}_{\mathrm{W}}\right)$, pore-water turnover rate $\left(R_{T}\right)$, sediment distribution coefficient $\left(K_{d}\right)$, suspended sediment load in water column (SSL), sedimentation rate (SR) and molecular diffusion coefficient (D); and finally, radionuclide concentration factors for seafood describing the bioaccumulation process $(\mathrm{CF})$.

Low and high absolute values of the local sensitivity index, $S^{(L)}$, calculated by the expression (1), correspond to low and high sensitivity of the state variables to the evaluated parameters. Further, positive/negative values of $S^{(\mathrm{L})}$ corresponds to the increase/decrease of the state variable when the evaluated parameter increases.

Results of the calculations indicates that doses to adults for all radionuclides and marine locations have very low sensitivity (the absolute values of $\mathrm{S}^{(\mathrm{L})}$ are very low) to the molecular diffusion coefficient (D) and pore-water turnover rate $\left(\mathrm{R}_{\mathrm{T}}\right)$.

Further, a sensitivity analysis of model parameters for ${ }^{131} \mathrm{I}$ indicate that only one parameter, namely the concentration factor for seaweeds has a high value of the sensitivity index of $\left(S^{(L)}=0.99\right)$. Calculations for all other parameters show very low values of sensitivity indexes for this radionuclide. Such results can be potentially explained by the characteristics of ${ }^{131} \mathrm{I}$, which has a short half life $(8$ days, approximately), low sediment distribution coefficient for shallow waters $\left(70 \mathrm{~m}^{3} / \mathrm{t}\right)$ and very high concentration factor for seaweeds $\left(10^{4} \mathrm{~Bq} / \mathrm{kg}\right)$. In a similar manner, all calculations for ${ }^{90} \mathrm{Sr}$ indicate very low values of the sensitivity index for all parameters describing water-sediment interactions, which can be explained by the lowest $\mathrm{Kd}$ value for ${ }^{90} \mathrm{Sr}$ in the present set of radionuclides $\left(8 \mathrm{~m}^{3} / \mathrm{t}\right)$ 
Table 1. Absolute values of the local sensitivity index for the advection rates, fl, for Ob Bay on the Kara Sea (OB), Cumbrian waters of the Irish Sea (CW), Lyme Bay on the English Channel (LB), Skagerrak (S), the Gulf of Riga on the Baltic Sea (GR) and North Sea off the Norwegian coasts (NC).

\begin{tabular}{lcccccc}
\hline Locations & OB & CW & LB & S & GR & NC \\
\hline${ }^{137} \mathrm{Cs}$ & 0.26 & 0.10 & 0.06 & 0.21 & 0.10 & 0.22 \\
${ }^{90} \mathrm{Sr}$ & 0.39 & 0.16 & 0.06 & 0.21 & 0.13 & 0.23 \\
${ }^{239} \mathrm{Pu}$ & 0.11 & 0.02 & 0.04 & 0.12 & 0.00 & 0.15 \\
\hline
\end{tabular}

Table 2. Absolute values of the local sensitivity index for some parameters describing the process of water sediment interactions: sediment reworking rate $\left(\mathrm{R}_{\mathrm{W}}\right)$, sediment distribution coefficient $\left(\mathrm{K}_{\mathrm{d}}\right)$, suspended sediment load in water column (SSL), sedimentation rate (SR).

\begin{tabular}{cccccccc}
\hline & & OB & CW & LB & S & GR & NC \\
\hline${ }^{137} \mathrm{Cs}$ & Rw & 0.19 & 0.11 & 0.06 & 0.08 & 0.17 & 0.07 \\
${ }^{239} \mathrm{Pu}$ & Rw & 0.33 & 0.23 & 0.39 & 0.28 & 0.33 & 0.18 \\
${ }^{137} \mathrm{Cs}$ & $\mathrm{K}_{\mathrm{d}}$ & 0.21 & 0.22 & 0.06 & 0.09 & 0.21 & 0.07 \\
${ }^{239} \mathrm{Pu}$ & $\mathrm{K}_{\mathrm{d}}$ & 0.07 & 0.27 & 0.36 & 0.20 & 0.37 & 0.13 \\
${ }^{239} \mathrm{Pu}$ & $\mathrm{SSL}$ & 0.39 & 0.13 & 0.04 & 0.04 & 0.04 & 0.00 \\
${ }^{239} \mathrm{Pu}$ & $\mathrm{SR}$ & 0.11 & 0.16 & 0.01 & 0.29 & 0.06 & 0.00 \\
\hline
\end{tabular}

Table 3. Absolute values of the local sensitivity index for concentration factors for fish ( $\mathrm{CFf})$, crustaceans $(\mathrm{CFc})$, molluscs (CFm) and seaweeds (CFs).

\begin{tabular}{lcccc}
\hline & ${ }^{137} \mathrm{Cs}$ & ${ }^{90} \mathrm{Sr}$ & ${ }^{131} \mathrm{I}$ & ${ }^{239} \mathrm{Pu}$ \\
\hline $\mathrm{CFf}$ & 0.72 & 0.36 & 0.01 & 0.07 \\
$\mathrm{CFc}$ & 0.12 & 0.20 & 0.00 & 0.05 \\
$\mathrm{CFm}$ & 0.12 & 0.33 & 0.00 & 0.60 \\
$\mathrm{CFs}$ & 0.04 & 0.12 & 0.99 & 0.28 \\
\hline
\end{tabular}

Results of calculations of the local sensitivity index for the advection rates, fl, ${ }^{137} \mathrm{Cs},{ }^{90} \mathrm{Sr}$ and ${ }^{239} \mathrm{Pu}$ are shown in Table 1 . Results in Table 1 show that doses to man from ${ }^{137} \mathrm{Cs}$ and ${ }^{90} \mathrm{Sr}$ are more sensitive to the process of water exchange than doses from ${ }^{239} \mathrm{Pu}$. Similar, the Lim Bay is much less sensitive to this process than, for example, the Ob Bay. The highest sensitivity index in Table 1 corresponds to the $\mathrm{Ob}$ Bay location for ${ }^{90} \mathrm{Sr}$.

The absolute values of the local sensitivity index for the parameters describing the process of water - sediment interactions are relatively high for ${ }^{137} \mathrm{Cs}$ and ${ }^{239} \mathrm{Pu}\left(\mathrm{Kd}\right.$ values for ${ }^{137} \mathrm{Cs}$ and ${ }^{239} \mathrm{Pu}$ are $4 \cdot 10^{3}$ and $1 \cdot 10^{5}$, respectively). Results of calculations are shown in Table 2 (values for the sensitivity index for parameters SSl and SR are very low for ${ }^{137}$ Cs and they are not shown in Table 2).

Water-sediment interaction is a complicated process arising from combinations of many parameters. Nevertheless, results in Table 2 show that doses to man from ${ }^{239} \mathrm{Pu}$ are, mainly, more sensitive to the process of water - sediment interactions than doses from ${ }^{137} \mathrm{Cs}$. It is also interesting to note that values of the sensitivity indexes in Table 2 are significantly higher for the marine regions with low depth as the Ob Bay (OB) and the Cumbrian Waters (CW) than for regions with relatively high depth as the North Sea off the Norwegian coasts (NC). Values of the depth for these regions are $11 \mathrm{~m}, 28 \mathrm{~m}$ and $156 \mathrm{~m}$, correspondently.

Further, sediment reworking rate $\left(\mathrm{R}_{\mathrm{W}}\right)$, sediment distribution coefficient $\left(\mathrm{K}_{\mathrm{d}}\right)$, suspended sediment load in water column (SSL) and depth of the water column are used in defining the process of particle mixing under water sediment interaction description. This means that the process of particle mixing dominates the water-sediment interactions for radionuclides with relatively high $\mathrm{K}_{\mathrm{d}}$ which means that doses to man from ${ }^{239} \mathrm{Pu}$ and ${ }^{137} \mathrm{Cs}$ are sensitive to this process.

Doses to man are calculated on the basis of the same seafood consumption in all evaluated regions. Therefore, sensitivity indexes for the concentration factors (CF) will be the same for all environments. Results of calculations are shown in Table 3. 
Results of calculations in Table 3 show that according to the present assumption about seafood consumption, the doses for all selected regions are sensitive to the parameters describing the process of bioaccumulation of radionuclides to biota, especially for the concentration factors for ${ }^{137} \mathrm{Cs}$ and fish for ${ }^{239} \mathrm{Pu}$ and molluscs and for ${ }^{131} \mathrm{I}$ and seaweeds.

\section{CONCLUSION}

The sensitivity analysis shows that the influence of model parameters can vary widely depending on the concrete radionuclude and selected marine regions. It is also shown that the results of the sensitivity parameter analysis can contribute to the process of defining which parameters can play an important role in the dose assessment and the evaluation of environmental vulnerability. In particular, it is shown that doses to man are most sensitive to processes of bioaccumulation for the present release scenario, selected radionuclides and the marine environments. Additionally, it is shown that doses to man are also sensitive to the process of the particle mixing for the radionuclides with high sediment distribution coefficient.

\section{References}

[1] EMRAS II. Working group 8. Environmental sensitivity: Documents. http://wwwns.iaea. org/projects/emras/emras2/workinggroups/workinggroupeight. asp?s=8

[2] Iosjpe M.. "Radioecological sensitivity of the coastal marine regions". International Conference on Radioecology \& Environmental Radioactivity. 1924 June 2011. Extended abstract. Hamilton. Ontario. Canada.

[3] Iosjpe M.. Radioactivity in the Environment. 8 (2006) 463-476.

[4] Iosjpe M.. Brown J. and Strand P.. J. Environ. Radioact.. 2002. 60. 91-103.

[5] Smith. K. and Jones. A.. Generalised habit data for radiological assessment. NRPB Report W41. 2003.

[6] Bergsten. C.. Fish and game study. Part B. Norwegian Food Safety Authority. Oslo 2003.

[7] Jørgensen S.E.. "Fundamentals of ecological modelling". Developments in environmental modelling. 19. Elsevier. 1994. 